\title{
Relationship Between Placental Calcification and Estimated Fetal Weight Percentile at 30-34 Weeks of Pregnancy
}

\author{
Mojgan Barati ${ }^{\circledR}$, Sara Masihi ${ }^{1}$, Elnaz Barahimi ${ }^{*}{ }^{*}$, Mohammad Ali Khorrami $^{2}$
}

\begin{abstract}
Objectives: The identification of at-risk fetus is considered as one of the most difficult challenges for clinicians and researchers although the clinical significance of placental calcifications (PCs) and its relation to adverse pregnancy outcome are controversial. Therefore, the present study aimed to evaluate the relationship between PC and estimated fetal weight (EFW) percentile at 30-34 weeks of pregnancy.

Materials and Methods: This prospective cross-sectional study was carried out on all pregnant women except for multiple pregnancy subjects who were admitted to an outpatient perinatal center from October 2016 to September 2018. Several parameters were measured at 30-34 weeks of pregnancy, including EFW, umbilical artery pulsatility index (PI), middle cerebral artery PI, cerebroplacental ratio (CPR), right and left uterine artery PI, along with right and left uterine artery notch. Finally, the calcification of the placenta with any shape and degree was determined as well.

Results: In this study, 739 pregnant women were evaluated for PC, including patients with PC (9.87\%), small-for-gestational age (SGA, 3.65\%), and those with at least one abnormal Doppler index (23.95\%). Patients with PC and those with at least one abnormal Doppler index had significantly higher SGA (29.62\% and $12.42 \%$, respectively). In addition, there were $55.55 \%$ and $30.13 \%$ patients with SGA and PC in the group with at least one abnormality in terms of Doppler indices.

Conclusions: In general, the findings showed that PC is more common in SGA. Based on the results, at least one abnormality in Doppler indices was more common in PC and SGA, and uterine artery Doppler abnormality was the most prevalent abnormal findings in the arterial Doppler. Thus, PC may be an important marker for adverse pregnancy outcomes.

Keywords: Placental calcification, Small for gestational age, Uterine artery pulsatility index Doppler
\end{abstract}

\section{Introduction}

One of the most difficult challenges to clinicians and researchers is the identification of at-risk fetus. Fetal growth restriction is a major cause of perinatal mortality and morbidity although the majority of small-forgestational age (SGA) fetuses are innately small and present no adverse perinatal outcome. In this regard, the combination of the estimated fetal weight (EFW), the cerebroplacental ratio (CPR), and uterine artery Doppler in the third trimester can more accurately identify atrisk stillbirth fetuses (1). In pregnancies complicated with preeclampsia and intrauterine growth retardation (IUGR), trophoblast invasion, limited to decidualized endometrium cause failure of spiral arteries and vessels, and could be detected by Doppler velocimetry of uterine artery (2). Uterine artery Doppler might be a good indicator for determining pregnant women who are at the risk of developing the preeclampsia and SGA (3).

Several investigators suggest that some of the placental histological changes may affect pregnancy complications $(4,5)$. The high-level deposition of calcium on the placenta tissue causes the echogenic focusing called "placental calcification (PC)" which is diagnosed by ultrasonographic evaluations and the identification of echogenic focusing. In addition, $\mathrm{PC}$ increases with gestational age and is considered as preterm PC (PPC) when it is detected before the 36th week of pregnancy. This echogenic focusing is also associated with adverse maternal and fetal outcomes and may be present as a pathological event caused by a wide range of environmental factors (6). The most common PC predisposing factors are smoking, parity, and maternal age (7). The prevalence of PPC widely ranges from $3.8 \%$ to $23.7 \%$ (6).

Some placental abnormalities may cause poor fetal growth (8). The clinical importance of PC and its relationship with the adverse pregnancy outcome seem to be controversial. Several studies reported the effect of early PC on the incidence of IUGR, low birth weight, low Apgar score, fetal distress, and pregnancy-induced hypertensive disorders $(4,6,9)$ although other investigators decline such an association (10-12). Thus, further studies in this field are required to resolve this controversy. Therefore, the

Received 7 June 2018, Accepted 3 January 2019, Available online 26 July 2019

${ }^{1}$ Faculty of Medicine, Fertility, Infertility, and Perinatology Center, Ahvaz Jundishapour University of Medical Sciences, Ahvaz, Iran. ${ }^{2}$ Department of Cellular Anatomical and Physiological Sciences, Faculty of Science, University of British Columbia, Vancouver, Canada.

*Corresponding Author: Elnaz Barahimi, Tel: +98-612439152, Email: brahimielnaz@gmail.com 
present study investigated the relationship between PC and EFW percentile at 30-34 weeks of pregnancy.

\section{Materials and Methods}

Study Design

The current prospective cross-sectional study was conducted on all pregnant women admitted to the outpatient perinatal center in Ahvaz during October 2016 to September 2018. The inclusion criteria were all mothers with a singleton pregnancy and those with multifetal pregnancy were excluded from the study. Prior to entering the study, patients were provided with necessary explanations, and the signed informed consent was taken from the patients by the fetal biometry that was performed from 30-34 weeks of pregnancy.

\section{Measurements}

Different data were recorded from the patients' files, encompassing demographic information like age and body mass index as well as the clinical history of women such as diabetes, hypertension, pregnancy-associated plasma protein $A$, and pregnancy with in virtue fertilization. Other parameters including the EFW, umbilical artery pulsatility index (PI), middle cerebral artery PI, CPR, right and left uterine artery PI, along with right and left uterine artery notch were measured by ultrasonography and entered in Austria software. All Doppler findings were explained according Benson et al's suggestions (13).

. Then, PC with any shape and degree, the gestational age of the fetus based on crown-rump length in nuchal translucency sonography, and EFW by Hadlock 2 (AC-HCFL) were determined as well (14). In addition, umbilical artery flow is evaluated by the Doppler velocimetry from the free-floating portion of the umbilical cord, middle cerebral artery flow is evaluated by Doppler velocimetry, Uterine artery flow evaluated by Doppler velocimetry and abnormal result defined when resistance index above 95th centile or the presence of an early diastolic notch in both uterine artery, CPR is also calculated by dividing the middle cerebral PI by Umbilical PI. All ultrasound examinations were performed using a Medison, version 20 (GE Medical System, Zipf, Austria) equipped with a 2.8- to 10- MHZ transabdominal transducer by one perinatologist to avoid the interobserver bias.

After sonographic evaluations, patients were divided into two groups first, based on PCs (with and without PCs) and then, based on Doppler ultrasonographic evaluations (group 1: patients with at least one abnormality in Doppler indices and group 2: those with normal Doppler indices).

\section{Statistical Analysis}

All variables were subjected to descriptive analysis including mean, standard deviation, and frequency and independent student' t-test was used to compare the means. Further, the chi-square test was utilized to compare the proportions. All analyses were performed using SPSS software, version 19 (SPSS Inc., Chicago, IL, USA) and the $P$ value less than 0.05 was considered statistically significant.

\section{Results}

During the study, 739 pregnant women were evaluated for $\mathrm{PC}$ and the following results were obtained:

- Seventy-three $(9.87 \%)$ patients with PC;

- $\quad$ Twenty-seven (3.65\%) patients SGA;

- One hundred and seventy-seven (23.95\%) patients with at least one abnormal Doppler index (umbilical $\mathrm{PI} \geq 95 \mathrm{th}, \mathrm{CPR} \leq 5 \mathrm{th}, \mathrm{MCA} \leq 5 \mathrm{th}$, uterine PI $\geq 95$ th, and unilateral or bilateral notch in the uterine artery);

- One hundred and twenty-eight (17.32\%) patients with at least one abnormality in terms of the uterine Doppler indices (i.e., mean, right or left uterine PI $\geq 95$ th, or unilateral/bilateral uterine notch).

As regards age, both non-calcified and calcified placenta groups were within the same age range. In the PC group, the BMI of the different age ranges of 19-25, 25-30, and $30-35$ was $2(2.7 \%), 63(86 / 3 \%)$, and $8(11 \%)$, respectively. According to Table 1, mothers with PC were as follows:

- One out of $17(5.88 \%)$ diabetic patients with treatment;

- Twenty-two out of $214(10.28 \%)$ diabetic patients without treatment;

- $\quad$ One out of 7 (14.28\%) patients with hypertension;

- $\quad$ Eight out of 27 (29.62\%) patients with SGA;

- None out of 8 patients with Umbilical PI $\geq 95$ th;

- Five out of $36(13.88 \%)$ patients with middle cerebral PI $\leq 5$ th;

- $\quad$ Four out of $48(8.33 \%)$ patients with $C P R \leq 5$ th;

- Eight out of $53(15.09 \%)$ patients with mean uterine PI $\geq 95$ th;

- Ten out of 67 (14.92\%) patients with mean uterine PI normal but one side (right or left) uterine PI $\geq 95$ th;

- One out of 8 (12.5\%) patients with both uterine PI normal but unilateral or bilateral notch;

- Nineteen out of 128 (14.84\%) patients with at least one abnormal uterine Doppler index;

- Twenty-two out of 177 (12.42\%) patients with at least one abnormal Doppler index;

- $\quad$ Six out of $59(10.16 \%)$ patients with PAPP-A $\leq 0.4$;

- Two out of 19 (10.52\%) patients with pregnancy by IVF.

According to Table 2, patients with at least one abnormality in Doppler indices included 1/17 (5.88\%) diabetes with treatment, 20/214 (9.34\%) diabetes without treatment, $1 / 7$ (14.28\%) hypertension, 15/27 (55.55\%) SGA, 22/73 (30.13\%) PC, 1/19 (5.26\%) pregnancy with IVF, and 8/59 (13.55\%) PAPP-A $\leq 0.4$.

As shown in Table 3, mothers with at least one abnormal Doppler indices encompassed 8/177 (4.51\%) umbilical PI $\geq 95$ th, $48 / 177$ (27.11\%) CPR $\leq 5$ th, 36/177 (20.33\%) MCA $\leq 5$ th, 53/177 (29.94\%) mean uterine PI $\geq 95$ th, 67/177 (37.85\%) mean uterine PI normal but one side 
Table 1. Maternal Characteristic of Pregnant Women in 30-34 Weeks of Pregnancy

\begin{tabular}{|c|c|c|c|c|}
\hline Maternal Characteristic & $\begin{array}{l}\text { Group } 1(n=73) \\
\text { Calcified Placenta }(9.87 \%)\end{array}$ & $\begin{array}{c}\text { Group } 2 \text { ( } n=666) \\
\text { Non-calcified Placenta }\end{array}$ & Total ( $\mathrm{N}=739)$ & $P$ Value \\
\hline Age (y) & $30 \pm 1$ & $30 \pm 1$ & $30 \pm 2.5$ & 0.95 \\
\hline BMI $\left(\mathrm{kg} / \mathrm{m}^{2}\right)$ & & & & 0.52 \\
\hline $19-25$ & $2(2.7 \%)$ & $48(7.2 \%)$ & 50 & \\
\hline $25-30$ & $63(86.3 \%)$ & $541(81.4 \%)$ & 605 & \\
\hline $30-35$ & $8(11 \%)$ & $76(11.5 \%)$ & 83 & \\
\hline Past medical history & & & & 0.7 \\
\hline Diabetes with treatment & $1(5.88 \%)$ & 16 & 17 & \\
\hline Diabetes without treatment & $22(10.28 \%)$ & 192 & 214 & \\
\hline Hypertension & $1(14.28 \%)$ & 6 & 7 & \\
\hline Small for gestational age (Estimate fetal weight $\leq 10$ th) & $8(29.62 \%)$ & 19 & 27 & $0.003^{\mathrm{a}}$ \\
\hline \multicolumn{5}{|l|}{ Doppler indices } \\
\hline UMB PI $\geq 95$ th & 0 & 8 & 8 & 1.0 \\
\hline $\mathrm{MCAPI} \leq 5$ th & $5(13.88 \%)$ & 31 & 36 & 0.38 \\
\hline $\mathrm{CPR} \leq 5$ th & $4(8.33 \%)$ & 44 & 48 & 0.7 \\
\hline Mean uterine $\mathrm{PI} \geq 95$ th & $8(15.09 \%)$ & 45 & 53 & 0.8 \\
\hline $\begin{array}{l}\text { Mean uterine PI normal but one side (right or left) uter- } \\
\text { ine PI } \geq 95 \text { th }\end{array}$ & $10(14.92 \%)$ & 57 & 67 & 0.7 \\
\hline $\begin{array}{l}\text { Both uterine PI normal but unilateral or bilateral notch } \\
\text { in uterine artery }\end{array}$ & $1(12.5 \%)$ & 7 & 8 & 0.1 \\
\hline At least one abnormal ${ }^{b}$ uterine Doppler index & $19(14.84 \%)$ & 109 & 128 & 0.052 \\
\hline At least one abnormal Doppler index & $22(12.42 \%)$ & 155 & 177 & $0.04^{a}$ \\
\hline IVF pregnancy with & $2(10.52 \%)$ & 17 & 19 & 0.71 \\
\hline PAPP-A $\leq 0.4$ & $6(10.16 \%)$ & 53 & 59 & 0.9 \\
\hline
\end{tabular}

Abbreviations: Umb PI, Umblical pulsatility index; MCA, Middle cerebral artery; CPR, Cerebroplacental ratio; PAPP-A, pregnancy-associated protein A; IVF, In vitro fertilization.

a Statistically significant; ${ }^{b}$ Mean: right or left uterine PI $\geq 95$ th or unilateral or bilateral uterine notch.

Patients were divided into two groups: Group 1, patients with calcified placenta and Group 2 those with non-calcified placenta.

Table 2. Maternal Characteristics of Pregnant Women in 30-34 Weeks of Pregnancy Divided Into 2 Groups

\begin{tabular}{|c|c|c|c|c|}
\hline Maternal Characteristic & $\begin{array}{l}\text { Group } 1 \text { ( } n=177) \\
\text { With at least one abnormal Doppler index }(23.95 \%)\end{array}$ & $\begin{array}{l}\text { Group } 2(n=562) \\
\text { Normal Doppler index }\end{array}$ & $\begin{array}{c}\text { Total } \\
(\mathrm{N}=739)\end{array}$ & $P$ Value \\
\hline Age (years) & $30 \pm 2$ & $30 \pm 1$ & $30 \pm 2.5$ & 0.2 \\
\hline BMI & & & & 0.86 \\
\hline $19-25$ & $11(6.3 \%)$ & $39(6.9 \%)$ & 50 & \\
\hline $25-30$ & $143(81.3 \%)$ & $461(82 \%)$ & 604 & \\
\hline $30-35$ & $22(12.5 \%)$ & $62(11.1 \%)$ & 84 & \\
\hline Past medical history & & & & 0.7 \\
\hline Diabetes with treatment & $1(5.88 \%)$ & 16 & 17 & \\
\hline Diabetes without treatment & $20(9.34 \%)$ & 194 & 214 & \\
\hline Hypertension & $1(14.28 \%)$ & 6 & 7 & \\
\hline $\begin{array}{l}\text { Small for gestational age (Estimate } \\
\text { fetal weight } \leq 10 \text { th) }\end{array}$ & $15(55.55 \%)$ & 12 & 27 & $<0.0001^{\mathrm{a}}$ \\
\hline Placental calcification & $22(30.13 \%)$ & 51 & 73 & $0.04^{\mathrm{a}}$ \\
\hline Pregnancy with IVF & $1(5.26 \%)$ & 18 & 19 & 0.58 \\
\hline PAPP-A $\leq 0.4$ & $8(13.55 \%)$ & 51 & 59 & 0.9 \\
\hline
\end{tabular}

Abbreviations: PAPP-A, pregnancy-associated protein A; IVF, In vitro fertilization.

${ }^{a}$ Statistically significant.

Group 1, those with at least one abnormal Doppler indices (umb PI $\geq 95$ th, MCA PI $\leq 5$ th, CPR $\leq 5$ th, Uterine PI $\geq 95$ th or unilateral/bilateral notch in the uterine artery) and Group 2, patients with normal Doppler indices. 
Table 3. One Abnormal Doppler Index in 30-34 Weeks of Pregnancy

\begin{tabular}{lcc}
\hline Doppler indices & At Least 1 abnormal Doppler Index ( $\mathbf{n = 1 7 7 )}$ & Total $\mathbf{n = 7 3 9}$ \\
\hline Umb PI $\geq 95$ th & $8(4.51 \%)$ & $36(20.33 \%)$ \\
\hline MCA PI $\leq 5$ th & $4.08 \%$ & $4.87 \%$ \\
\hline CPR $\leq 5$ th & $6.49 \%$ \\
\hline Mean uterine PI $\geq 95$ th & $53(29.94 \%)$ \\
\hline Mean uterine PI normal but one side (right/left) uterine PI $\geq 95$ th & $67(37.85 \%)$ \\
\hline Both uterine PI normal but unilateral or bilateral notch & $8(4.51 \%)$ \\
\hline
\end{tabular}

Abbreviations: Umb PI, Umblical pulsatility index; MCA, Middle cerebral artery; CPR, Cerebroplacental ratio.

(right or left) uterine PI $\geq 95$ th, and $8 / 177$ (4.51\%) right or left uterine PI normal but with one or two side(s) uterine notch. Based on the results, abnormality in uterine artery Doppler indices was more than that of the other arterial Dopplers.

\section{Discussion}

Our findings indicated that $9.87 \%$ of the studied patients showed PCs. Generally, more than half of the pregnant women presented some degree of PC (15). In the study by Chen et al, the prevalence of PPC was determined as $3.8 \%$ at 36 weeks, $9 \%$ (before 28 weeks), 15\% (at 34 36 weeks), and $23.7 \%$ (at 31-34 weeks). PC is diagnosed by ultrasonographic evaluations and the identification of echogenic focusing (6). In another study by Miller et al., the prevalence of PC at term was $39.4 \%$ (11). Despite the findings of Chen et al (6), the present study did not evaluate the maternal age and its correlation with PCs. Smoking, maternal age, and parity are reported as the major predisposing factors of PC (7).

The clinical significance of PC, as the most common pathological change in the placenta during pregnancy, is a controversial issue among the clinicians and researchers. Our results demonstrated that SGA and, at least, one abnormality in Doppler indices were more prevalent in mothers with PC. These results could arise the hypothesis that the PC has clinical value and may be a risk factor for SGA. The findings of the current study are in line with the results of the previous studies. For instance, Mirza et al found that significant PC was associated with low birth weight and perinatal death (16). In addition, Ciobanu et al in another study evaluated the potential value of maternal characteristics, medical history, EFW, and impaired placentation biomarkers at $35+0$ to $36+6$ gestation weeks regarding anticipating the delivery of SGA neonates. They indicated that the altered placentation biomarkers only slightly increased the predictive performance for the delivery of SGA neonates achieved by maternal factors and fetal biometry at 35+0-36+6 weeks of gestational age (17). Similarly, some other reports also revealed that PPC was related to a higher incidence of IUGR, fetal distress, low Apgar score, and pregnancy-induced hypertension while based on the results of other studies, no significant correlation was observed between PPC and the incidence of IUGR, low Apgar score, low birth weight, or fetal distress, and its low value in determining the increasedrisk pregnancy (6).

There were more abnormal Doppler, low body weight, and cesarean deliveries in mothers with preterm PC. Likewise, Agarwal et al in a similar study concluded that the PC is more common in patients with an abnormal Doppler (18). Umbilical Artery resistance index and absent or reversed end-diastolic velocity were more common in those with preterm PC (19). Therefore, the PC may be correlated with abnormal Doppler findings. On the other hand, PCs may affect the pregnancy outcome and act as a risk factor for SGA and fetal growth restriction. Future studies can evaluate the relationship between PC, thickness, and placental biometry with adverse pregnancy outcomes.

\section{Conclusions}

The findings of this study showed that PC was more frequent in SGA. The results further represented that at least one abnormality in Doppler indices was more common in PC and SGA and the uterine artery Doppler abnormality is the most common abnormal finding in the arterial Dopplers. PC may be an important marker for adverse pregnancy outcomes, accordingly, more study can provide more valid results.

Our study has some limitations. Some characteristics of patients such as race and educational status were not considered in our study and the low sample size was regarded as another limitation of the current study. However, the evaluation of the relationship between Doppler indices and PC was considered as one of the strengths of this study.

\section{Conflict of Interests}

Authors declare that they have no conflict of interests.

\section{Ethical Issues}

This study was approved by the Ethics Committee of Ahvaz Jundishapur University of Medical Sciences (IR. AJUMS.REC.1397.400). Written informed consent was obtained from all patients and normal individuals. 


\section{Financial Support}

None.

\section{Acknowledgments}

We wish to thank all our colleagues at Imam Khomeini Hospital, Ahvaz, Iran.

\section{References}

1. Khalil A, Thilaganathan B. Role of uteroplacental and fetal Doppler in identifying fetal growth restriction at term. Best Pract Res Clin Obstet Gynaecol. 2017;38:38-47. doi:10.1016/j.bpobgyn.2016.09.003

2. Gibbs RS, Danforth DN. Danforth's obstetrics and gynecology. Philadelphia: Lippincott Williams \& Wilkins; 2008.

3. Barati M, Shahbazian N, Ahmadi L, Masihi S. Diagnostic evaluation of uterine artery Doppler sonography for the prediction of adverse pregnancy outcomes. J Res Med Sci. 2014;19(6):515-519.

4. McKenna D, Tharmaratnam S, Mahsud S, Dornan J. Ultrasonic evidence of placental calcification at 36 weeks' gestation: maternal and fetal outcomes. Acta Obstet Gynecol Scand. 2005;84(1):7-10. doi:10.1111/j.00016349.2005.00563.x

5. Wallingford MC, Benson C, Chavkin NW, Chin MT, Frasch MG. Placental Vascular Calcification and Cardiovascular Health: It Is Time to Determine How Much of Maternal and Offspring Health Is Written in Stone. Front Physiol. 2018;9:1044. doi:10.3389/fphys.2018.01044

6. Chen KH, Chen LR, Lee YH. Exploring the relationship between preterm placental calcification and adverse maternal and fetal outcome. Ultrasound Obstet Gynecol. 2011;37(3):328-334. doi:10.1002/uog.7733

7. Bedir Findik R, Ersoy AO, Fidanci V, Tasci Y, Helvacioglu Y, Karakaya J. Vitamin D deficiency and placental calcification in low-risk obstetric population: are they related? J Matern Fetal Neonatal Med. 2016;29(19):3189-3192. doi:10.3109/1 4767058.2015.1118043

8. Dashe JS, Bloom SL, Spong CY, Hoffman BL. Williams Obstetrics. McGraw Hill Professional; 2018.

9. Chitlange SM, Hazari KT, Joshi JV, Shah RK, Mehta AC. Ultrasonographically observed preterm grade III placenta and perinatal outcome. Int J Gynaecol Obstet.
1990;31(4):325-328. doi:10.1016/0020-7292(90)90909-5

10. Hill LM, Breckle R, Ragozzino MW, Wolfgram KR, O’Brien PC. Grade 3 placentation: incidence and neonatal outcome. Obstet Gynecol. 1983;61(6):728-732.

11. Miller JM Jr, Brown HL, Kissling GA, Gabert HA. The relationship of placental grade to fetal size and growth at term. Am J Perinatol. 1988;5(1):19-21. doi:10.1055/s-2007-999645

12. Vosmar MB, Jongsma HW, van Dongen PW. The value of ultrasonic placental grading: no correlation with intrauterine growth retardation or with maternal smoking. J Perinat Med. 1989;17(2):137-143. doi:10.1515/ jpme.1989.17.2.137

13. Benson CB, Bluth EI, editors. Ultrasonography in obstetrics and gynecology: a practical approach to clinical problems. Thieme; 2008.

14. Alexander GR, Himes JH, Kaufman RB, Mor J, Kogan M. A United States national reference for fetal growth. Obstet Gynecol. 1996;87(2):163-168. doi:10.1016/00297844(95)00386-X

15. Guo Y, Zhang D, Lu H, Luo S, Shen X. Association between calcifying nanoparticles and placental calcification. Int J Nanomedicine. 2012;7:1679-1686. doi:10.2147/ijn.s29786

16. Mirza FG, Ghulmiyyah LM, Tamim H, Makki M, Jeha D, Nassar A. To ignore or not to ignore placental calcifications on prenatal ultrasound: a systematic review and metaanalysis. J Matern Fetal Neonatal Med. 2018;31(6):797-804. doi:10.1080/14767058.2017.1295443

17. Ciobanu A, Rouvali A, Syngelaki A, Akolekar R, Nicolaides KH. Prediction of small for gestational age neonates: screening by maternal factors, fetal biometry, and biomarkers at 35-37 weeks' gestation. Am J Obstet Gynecol. 2019;220(5):486.e481-486.e411. doi:10.1016/j. ajog.2019.01.227

18. Agarwal R, Tiwari A, Wadhwa N, Radhakrishnan G, Bhatt S, Batra P. Abnormal umbilical artery Doppler velocimetry and placental histopathological correlation in fetal growth restriction. S Afr J Obstet Gynaecol. 2017;23(1):12-16. doi:10.7196/SAJOG.2017.v23i1.1109

19. Jamal A, Moshfeghi M, Moshfeghi S, Mohammadi N, Zarean E, Jahangiri N. Is preterm placental calcification related to adverse maternal and foetal outcome? J Obstet Gynaecol. 2017;37(5):605-609. doi:10.1080/01443615.2017 .1285871

\footnotetext{
(c) 2019 The Author (s); This is an open-access article distributed under the terms of the Creative Commons Attribution License (http://creativecommons.org/licenses/by/4.0), which permits unrestricted use, distribution, and reproduction in any medium, provided the original work is properly cited.
} 